\title{
Evaluation of Serum levels of epidermal growth factor (EGF) in Patients with alopecia
} areata

\author{
A.M.El-Refaey ${ }^{1}$, R.A.Khashaba ${ }^{2}$, D.M. El-Habbak ${ }^{1}$, H.M.Allam ${ }^{3}$ \\ ${ }^{1}$ Dermatology, Venereology and Andrology, Faculty of Medicine, Benha Univ., Benha, Egypt \\ ${ }^{2}$ Clinical and Chemical Pathology Dept., Faculty of Medicine, Benha Univ., Benha, Egypt \\ ${ }^{3}$ Dermatology, Venereology and Andrology., Faculty of Medicine, Ain Shams Univ., Cairo, Egypt \\ E-Mail:lolla77allam@gmail.com
}

\begin{abstract}
Alopecia areata is a common cause of non-scarring alopecia that occurs in a patchy, confluent or diffuse pattern. The EGF can promote growth of the ORS compartment of mink hair follicles in vitro, and enhance proliferation and migration of the ORS cells via activation of the Wnt/ $\beta$-catenin signaling pathway.Evaluation of serum levels of EGF in patients with alopecia areata.Serum EGF concentrations were measured in 60 consecutive patients with alopecia areata in comparison with 25 controls using enzyme-linked immunosorbent assay (ELISA).Serum levels of EGF were found to be higher in patients than in healthy controls.increased serum levels of EGF in patients than in controls probably reflect the role of EGF in the pathogenesis of alopecia areata.
\end{abstract}

Keywords: Alopecia areata, EGF, ELISA.

\section{Introduction}

Alopecia areata (AA) may be a as a relatable point kind from claiming hair reduction or alopecia Previously, people. It may be an immune system sickness for a variable, commonly backsliding or remitting course that could a chance to be persistency - particularly when hair passing will be far reaching. Alopecia areata may be the second-most incessant non-scarring alopecia following male What's more female design alopecia. Clinical designs for hair passing On alopecia areata need aid Typically precise unique. The practically regular design may be An little annular or patchwork bedcover bare lese greatness (patchy alopecia areata), Typically on the scalp, that might advancement to downright reduction for scalp hair best (alopecia totalis) What's more aggregate passing for the greater part body hair (alopecia universalis) [1].

The trigger element influences the methodology of keratinocytes division Furthermore differentiation, Furthermore induces transforms Previously, metabolic forms within those development plate of a hair bulb, which prompts premature end of the anagen stage [2].

It will be known that there may be an expansive number for sign particles included in regulation of a hair cycle and recovery of a follicle. The individuals incorporate specific genes, a portion sorts for Growth factors, atomic receptors, cytokines, subcellular indicating pathways. [3].

A few development Components show up to control the advancement and the cycle of a hair follicle for example, epidermal Growth component (EGF), transforming Growth element (TGF), keratinocyte development element (KGF), vascular endothelial development Fig (1) (VEGF) [4].

Epidermal Growth component relatives initiate a intracellular indicating course upon tying should their receptors, all things considered known as those ErbB crew. The ErbB gang comprises ErbB1 (or EGFR), ErbB2, ErbB3 What's more ErbB4. Investigations bring indicated that ErbB1 Concerning illustration a critical development element receptor Furthermore its ligand EGF exist to external root sheath (ORS) of the full grown hair follicle and assume a paramount part in the regulation from claiming hair follicle Growth cycle [5]. Epidermal Growth figure (EGF) may be a Growth component that assumes a paramount part in the regulation from claiming cell growth, proliferation, Also separation Eventually Tom's perusing tying will epidermal Growth variable receptor (EGFR). Those parts from claiming EGF and EGFR on the pathogenesis about (AA) would questionable. However, a few reports recommend those companionship the middle of EGF indicating What's more AA [6].

\section{Material and methods}

This study might have been directed Likewise an instance control investigation that included 60 patients for alopecia areata Also 25 healthy, period Furthermore sex matched controls recruited from dermatology outpatient clinic, Benha school healing facility. Every one points of the ponder were examined with those patients Furthermore educated assent might have been acquired starting with every tolerant in the recent past enrolment in the study. Those protocol might have been reconsidered Also sanction Toward the morals panel from claiming mankind's Examine. , employees for Medicine, Benha college. Patients with any of the Emulating states were excluded from those study: Patients with contagious or bacterial spoiling to scalp. Patients with scarring and non-scarring alopecia. Patients suffice from any systemic maladies other than those skin infection. Patients anguish from thyroid diseases, immune system diseases, irresistible diseases, tumors Also hyperandrogenism.

All patients were subjected of the following:.

\section{1 History taking}

Patients' demographic information were recorded: name, period Also sex. A point by point history might have been taken from patients in regards to onset, course, span and repeat about alopecia areata. History for past medicine about alopecia areata and light of this past medicine. Patients were approached regarding history 
from claiming atopy, atopic dermatitis, nail pitting Furthermore family history about alopecia areata..

\subsection{Clinical examination}

All examination might have been done on focus At whatever systemic or dermatological malady Furthermore nearby examination on avoid any differential determination What's more determine At whatever nearby state contraindicating those tolerant starting with continuously incorporated in the study.

Clinical appraisal about AA lesions as stated by clinical seriousness which separated into: gentle (three alternately lesquerella patches for alopecia with An widest breadth from claiming $3 \mathrm{~cm}$ alternately lesquerella or those illness restricted to those eyelashes What's more eyebrows), direct (existence for more than 3 patches from claiming alopecia alternately a patavium more excellent over $3 \mathrm{~cm}$ at those widest breadth without alopecia totalis alternately alopecia universalis) Furthermore extreme [ alopecia totalis or alopecia universalis or ophiasis( which characterized as Snakeshaped plaques extending of the scalp outskirt alternately passing about hair fit as a fiddle of a wave at the perimeter of the head)] .

\subsection{Methods \\ Epidermal growth factor Assay}

Blood samples were collected in complete aseptic condition by veni puncture then blood was left to clot then centrifuged for 15 minutes at $5000 \mathrm{rpm}$. The sera were separated and stored at $-20{ }^{\circ} \mathrm{C}$ until the time of the assay.

\section{Principle of test}

This ELISA kit uses double_antibodySandwichELISA to assay the level of human epidermal growth factor (EGF) in samples. Add (EGF) to monoclonal antibody enzyme well which is pre_coated with human (EGF) monoclonal antibody, incubation: then, add (EGF) antibodies labeled with biotion, combined with streptavidin_HRP to form immune complex; then carry out incubation and washing again to remove the uncombined enzyme. Then add chromogen solution A, $\mathrm{B}$, the color of the liquid changes into the blue, and at the effect of acid, the color finally becomes yellow. The chroma of color and the concentration of the human substance (EGF) of sample were positively correlated.

\section{Statistical analysis}

The greater part information were collected, tabulated Furthermore statistically investigated utilizing SPSS 20. 0 to windows (SPSS inc., Chicago, IL, usa 2011). Quantitative information were communicated Concerning illustration those intend \pm sd\& (minimummaximum), Also qualitative information were communicated Similarly as supreme frequencies (number)\& relative frequencies (percentage). Constant information were checked for typicality Toward utilizing Shapiro stroll test. Mann Whitney u test might have been utilized to thinking about two aggregations of nottypically disseminated variables. KruskallWallius test might have been used to look at between more than two aggregations of non- typically conveyed variables. Percent about unmitigated variables were thought about utilizing Chi-square test. Logistic relapse investigation might have been used to determine predictors from claiming alopecia areata. Every one tests were two agreed. P-value $<0.05$ might have been viewed as statistically noteworthy Furthermore p-value $\geq 0$. 05 might have been acknowledged statistically inconsequential (NS).

\section{Results and discussion}

There was a statistically significant lower in the Mean serum level of EGF in patients than controls Table (1).

Although the etiopathogenesis of AA is poorly understood, most researches think that it is connected with immune processes [7].

Several growth factors appear to control the development and cycle of hair follicle such as epidermal growth factor (EGF), transforming growth factor (TGB), keratinocyte growth factor (KGF), vascular endothelial factor (VEGF) [4].

Those EGF camwood Push development of the ORS compartment from claiming mink hair follicles done vitro, and improve burgeoning Also movement of the ORS units by means of actuation of the $\mathrm{Wnt} / \beta$-catenin indicating pathway [8].

The parts of EGF and EGFR in the pathogenesis from claiming AA are obscure. However, a few reports bring recommended an cooperation between EGF indicating and AA [6].

Table (1) Demographic characteristics of alopecia areata patients and control

\begin{tabular}{|c|c|c|c|c|}
\hline \multirow[t]{2}{*}{ Items } & \multicolumn{2}{|c|}{$\begin{array}{ll}\text { Studied groups } \\
\end{array}$} & \multirow[b]{2}{*}{$\chi^{2}$} & \multirow[b]{2}{*}{$\mathbf{P}$} \\
\hline & AA patients $(n=60)$ & Control(n=25) & & \\
\hline \multicolumn{5}{|c|}{ Age per years } \\
\hline Mean \pm SD & $27 \pm 12$ & $30 \pm 10$ & $\mathrm{MW}=1.2$ & $0.22(\mathrm{NS})$ \\
\hline Min-max & $5-55$ & $4-55$ & & \\
\hline \multicolumn{5}{|l|}{ Sex } \\
\hline Male & $38(63.3)$ & $20(80)$ & 2.3 & 0.13 \\
\hline Female & $22(36.7)$ & $5(20)$ & & (NS) \\
\hline
\end{tabular}




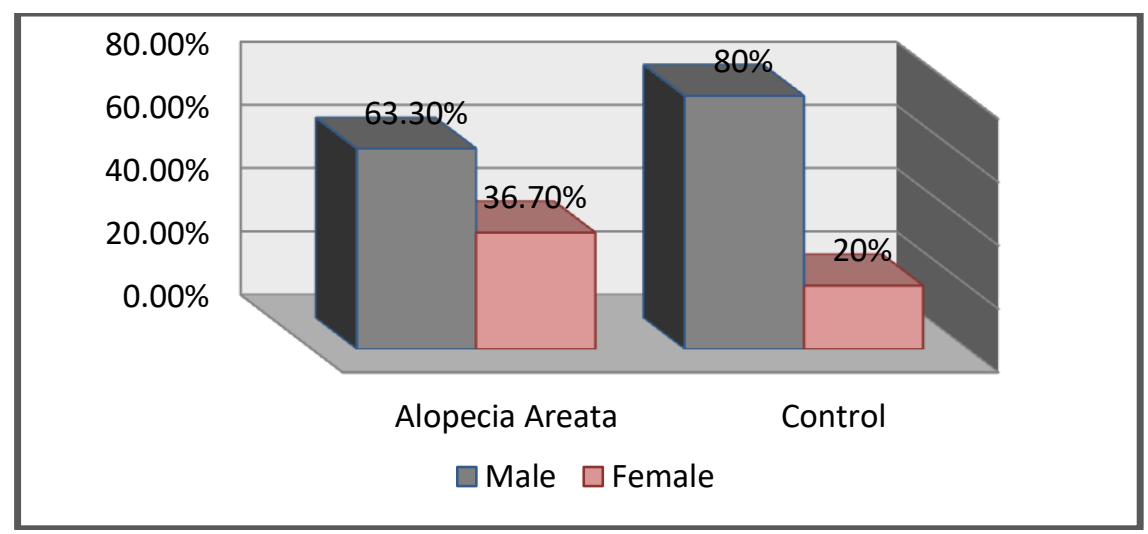

Fig (1) percent of male and female of studied groups.

The comes about of our study demonstrated that serum level of EGF might have been altogether higher Previously, patients for AA contrasted with sound control subjects and the Contrast might have been Exceptionally statistically huge ( $\mathrm{P}$ value $<0$. 0003). This might have been concurred upon with An investigation led by which examined companionship the middle of EGF Also EGFR gene polymorphisms Furthermore defenselessness on AA in the korean population, their outcomes were particular case single nuclotidepolymrphism(SNP) (rs11569017) about EGF indicated critical Contrast between the AA bunch Also control bunch (P worth 0. 0025).

An investigation finished by Zhanget indicated EGF could Push Growth of the ORS compartment about mink hair follicles clinched alongside vitro, Furthermore improve burgeoning Furthermore movement of the ORS phones by means of actuation of the $\mathrm{Wnt} / \beta$ - catenin indicating pathway. Previously, their study, $2 \mathrm{ng} / \mathrm{ml}$ Furthermore $20 \mathrm{ng} / \mathrm{ml}$ EGF shown An momentous stimulatory impact on the development of the ORS compartment over vitro, while the ORS didn't react to a higher fixation for EGF in regards should development Yet might have been some way or another repressed Eventually Tom's perusing those high-dose EGF.

For examination the middle of serum level about EGF "around patients for distinctive degrees about AA as stated by salt score, there might have been statistically huge distinction ( $\mathrm{P}$ esteem might have been 0. 0001), which can't help contradicting contemplate completed which demonstrated no huge Contrast connected with any of the SNPs for EGF Previously, patchwork bedcover or totalis alopecia butone SNP (rs17337023) about EGFR indicated noteworthy contrasts between patchy-type AA and alopecia totalis.

\section{Conclusion}

The EGF is significantly elevated in AA patients when compared to the control subjects. It is also positively correlated with the number and the extent of the disease, making it a possible marker of AA severity.

\section{References}

[1] C.Herbrtpratt,LioydE.King,Alopecia areata ,Vol.92, PP. 331-344, 2012.

[2]B. Werner, F. Mulinari-Brenner ,Clinical and histological challenge in the differential diagnosis of diffuse alopecia: female androgenetic alopecia, telogen effluvium and alopecia areata - part I, Vol.12,pp 331-344, 2012.

[3]C.L. Chen, X. Yu, I.O. James,Heparin-binding EGFlike growth factor protects intestinal stem cells from injury in a rat model of necrotizing enterocolitis. Lab Invest, Vol.62, PP.331-344, 2012.

[4]A.A.Kubanov, A. Yu.,The study of Growth factors in patients with androgenic alopecia, vol 50: 320-315, 2017.

[5]T.H. Wang, J.L. Chang, J.Y. Ho,EphrinA5 suppresses coloncancerdevelopment by negatively regulating epidermal growth factor receptor stability, Vol.FEBS J., Vol. 279, PP. 251-263, 2012.

[6]Yong-Yon Won, Sik Haw1, Joo-Ho Chung, Association between EGF and EGFR Gene Polymorphisms and Susceptibility to Alopecia Areata in the KoreanPopulation, Vol.100, PP.331, 2015

[7]E.A.Olsen, M.K.Hordinsky, V.H. Price, National alopecia areata foundation. alopecia areata investigationalassessment guidelines, Vol.60, PP.102, 2016

[8]Z. Haihua, N. Weixiao Epidermal Growth Factor Promotes Proliferation and Migration of Follicular Outer Root Sheath Cells via Wnt/ $\beta$-Catenin Signaling, Vol.40: 115-125, 2016 